\title{
Severe proteinuria during the administration of bevacizumab plus mFOLFOX6 in a colorectal cancer patient after kidney transplantation: a case report
}

\author{
Ren Onodera ${ }^{1 *}$ (D), Satoru Nihei ${ }^{1,2}$, Toshimoto Kimura ${ }^{3}$, Takashi Tomita ${ }^{1,2}$ and Kenzo Kudo ${ }^{1,2}$
}

\begin{abstract}
Background: Bevacizumab (BEV) leads to proteinuria and renal damage. It is not clear whether the administration of immunosuppressive drugs after renal transplantation affects the safety of BEV administration. We report a case of severe proteinuria caused by BEV plus 5-fluorouracil, levofolinate, and oxaliplatin (mFOLFOX6) in a patient who had previously undergone kidney transplantation and the administration of tacrolimus.

Case presentation: The patient was a 67-year-old man with a history of diabetes and hypertension. He developed chronic renal failure 14 years earlier and underwent right kidney transplantation from a living donor followed by the administration of tacrolimus and mycophenolate mofetil for immunosuppression. After kidney transplantation, the patient was diagnosed with colorectal cancer with multiple lung and liver metastases and received BEV plus mFOLFOX6. After 5 cycles, proteinuria was observed, with a urinary protein concentration of $>300 \mathrm{mg} / \mathrm{dL}$ (urine protein creatinine ratio: 3.5), and after 16 cycles, the urinary protein concentration was $>1000 \mathrm{mg} / \mathrm{dL}$ (urine protein creatinine ratio: 7.1). Subsequently, BEV was discontinued, and only mFOLFOX6 administration was continued. Tacrolimus continued to be administered during chemotherapy. There was no association between serum tacrolimus concentration and proteinuria.
\end{abstract}

Conclusions: In this case, BEV administration caused severe proteinuria without affecting blood levels of tacrolimus. Patients with risk factors for renal impairment should be carefully evaluated for the risks and benefits of BEV administration.

Keywords: Kidney transplantation, Tacrolimus, Bevacizumab, Proteinuria, Adverse effects, Colorectal cancer

\section{Background}

Kidney transplant, commonly performed for end-stage renal disease, is an alternative to dialysis. Kidney transplantation helps prolong the survival of renal recipients [1]. However, post-transplant renal impairment, proteinuria, and cardiovascular disease are major risk factors for graft loss [2]. Therefore, strict management is

\footnotetext{
*Correspondence: aiueonoderaiueo@gmail.com

'Department of Pharmacy, Iwate Medical University Hospital, 2-1-1 Idaidouri, Yahaba-cho, Iwate 028-3609, Japan

Full list of author information is available at the end of the article
}

essential. Also, an increased incidence of colorectal cancer has been reported in kidney transplant patients [3].

Bevacizumab (BEV) is a humanized, monoclonal, antivascular endothelial growth factor antibody that exhibits antiangiogenic function. Generally, BEV is used in primary therapy with 5 -fluorouracil, levofolinate, and oxaliplatin (mFOLFOX6) or 5-fluorouracil, levofolinate, and irinotecan therapy. Recently, combination regimens have been used as the second-line standard treatment for unresectable, advanced, or recurrent colorectal cancer [4]. Untreated metastatic colorectal cancer has a median

C C The Author(s). 2020 Open Access This article is licensed under a Creative Commons Attribution 4.0 International License, which permits use, sharing, adaptation, distribution and reproduction in any medium or format, as long as you give appropriate credit to the original author(s) and the source, provide a link to the Creative Commons licence, and indicate if changes were made. The images or other third party material in this article are included in the article's Creative Commons licence, unless indicated otherwise in a credit line to the material. If material is not included in the article's Creative Commons licence and your intended use is not permitted by statutory regulation or exceeds the permitted use, you will need to obtain permission directly from the copyright holder. To view a copy of this licence, visit http://creativecommons.org/licenses/by/4.0/ The Creative Commons Public Domain Dedication waiver (http://creativecommons.org/publicdomain/zero/1.0/) applies to the data made available in this article, unless otherwise stated in a credit line to the data. 
overall survival of approximately 6 months, while BEV plus mFOLFOX6 extends it to approximately 21 months [5].

However, side effects such as hypertension, proteinuria, and bleeding have been reported following BEV administration [6-8]. Proteinuria is one of the most commonly observed side effects caused by BEV [9]. BEV has been reported to alter the endothelial surface in the glomerular endothelium and may induce the development of thrombotic microangiopathy, which may be a risk for underlying proteinuria and renal dysfunction [10].

History of living kidney transplantation, administration of immunosuppressants, and administration of chemotherapy including BEV may adversely affect the maintenance of renal function in patients due to post-transplant complications and drug-drug interactions. However, few reports discuss the effects of BEV administration after living kidney transplantation and immunosuppressants administration, and the effect of BEV on the risk of proteinuria in such cases remains unclear [11].

We report our experience in handling a case of severe proteinuria because of concomitant BEV administration for colorectal cancer in a patient receiving tacrolimus following right living donor kidney transplantation.

\section{Case presentation}

\section{Patient background}

The patient was a 67-year-old man with a history of diabetes and hypertension. He developed chronic renal failure 14 years earlier and underwent right living donor kidney transplantation followed by the administration of tacrolimus and mycophenolate mofetil for immunosuppression. Renal function remained normal after kidney transplantation. Amlodipine and candesartan were administered for high blood pressure.

Eleven years after kidney transplantation, the patient was diagnosed with colorectal cancer with multiple lung and liver metastases and received BEV plus mFOLFOX6. The dose of BEV was $5 \mathrm{mg} / \mathrm{kg} /$ day. Physical characteristics before therapy were as follows: body weight, $61.8 \mathrm{~kg}$; height, $162 \mathrm{~cm}$; blood pressure, 160/91 mmHg; pulse, 91 bpm; and body temperature, $36.6{ }^{\circ} \mathrm{C}$. Clinical laboratory tests showed the following: white blood cell (WBC) count, $2.5 \times 10^{9} / \mathrm{L}$; neutrophil count, $1.2 \times 10^{9} / \mathrm{L}$; platelet count, $101 \times 10^{9} / \mathrm{L}$; hemoglobin concentration, $114 \mathrm{~g} / \mathrm{L}$; lactate dehydrogenase, $143 \mathrm{U} / \mathrm{L}$; serum creatinine concentration (SCr), $81.3 \mu \mathrm{mol} / \mathrm{L}$; blood urea nitrogen (BUN), $9.0 \mathrm{mmol} / \mathrm{L}$; estimated glomerular filtration rate (eGFR), $64.1 \mathrm{~mL} / \mathrm{min} / 1.73 \mathrm{~m}^{2}$; and serum albumin concentration, $40 \mathrm{~g} / \mathrm{L}$. The urinary protein concentration (dipstick urinalysis) was $30 \mathrm{mg} / \mathrm{dL}$, and the urine protein creatinine ratio (UPCR) was $0.4 \mathrm{~g} / \mathrm{gCr}$.

\section{Proteinuria}

After 2 cycles of mFOLFOX6, BEV was added to the regimen, and the urinary protein concentration and UPCR of the patient increased to $300 \mathrm{mg} / \mathrm{dL}$ and $3.5 \mathrm{~g} /$ gCr, respectively, after 5 cycles of BEV plus mFOLFOX6 (Fig. 1). The urinary protein concentration continued to increase, and after 16 cycles of BEV plus mFOLFOX6, the urinary protein concentration and UPCR reached $1000 \mathrm{mg} / \mathrm{dL}$ and $7.1 \mathrm{~g} / \mathrm{gCr}$, respectively. At this point, BEV administration was discontinued. Ten weeks after discontinuation of BEV administration, urinary protein concentration improved to $300 \mathrm{mg} / \mathrm{dL}$, but UPCR showed further deterioration. After that, the UPCR improved to $5.7 \mathrm{~g} / \mathrm{gCr}$, but BEV could not be restarted. Afterwards, significant proteinuria was not induced.

We utilized trough level concentration as a measure of the exposure to tacrolimus. During chemotherapy, the tacrolimus dose was maintained at $3 \mathrm{mg} /$ day, but the tacrolimus dose was reduced to $2 \mathrm{mg}$ /day because the serum tacrolimus concentration increased during the 4 cycles of chemotherapy. After that, no further rapid increase in serum tacrolimus concentration was observed. There was no association between serum tacrolimus concentration and proteinuria.

Although chemotherapy started without any significant change in renal function, eGFR decreased after the onset of proteinuria. When BEV was discontinued, eGFR was $48.6 \mathrm{~mL} / \mathrm{min} / 1.73 \mathrm{~m}^{2}$. Afterwards, significant renal dysfunction was not induced. Serum albumin concentration showed a gradual decrease during chemotherapy, but there was no significant change before and after the onset of proteinuria. Nephrotic syndrome was suspected due to the onset of proteinuria but was excluded because neither hypoalbuminemia $(<30 \mathrm{~g} / \mathrm{L})$ nor edema were observed beyond the diagnostic criteria.

\section{Hypertension}

To control blood pressure, $2.5 \mathrm{mg}$ amlodipine, a calcium antagonist, was started at the time of BEV administration. Immediately after BEV administration, a rapid increase in systolic blood pressure required the initiation of $8 \mathrm{mg}$ candesartan, an angiotensin II receptor blocker. Since there was a similar increase in blood pressure after 7 more cycles, the dose of amlodipine was increased to $5 \mathrm{mg}$. After that, blood pressure control was stable only with amlodipine (Fig. 1).

\section{Other adverse events}

Thrombocytopenia $\left(4.7 \times 10^{9} / \mathrm{L}\right)$ was observed at the start of cycle 11 of BEV plus mFOLFOX6. Since thrombocytopenia did not improve after reducing the oxaliplatin dose, oxaliplatin was discontinued after the completion of 18 cycles of mFOLFOX6. Following discontinuation of oxaliplatin, the platelet count 


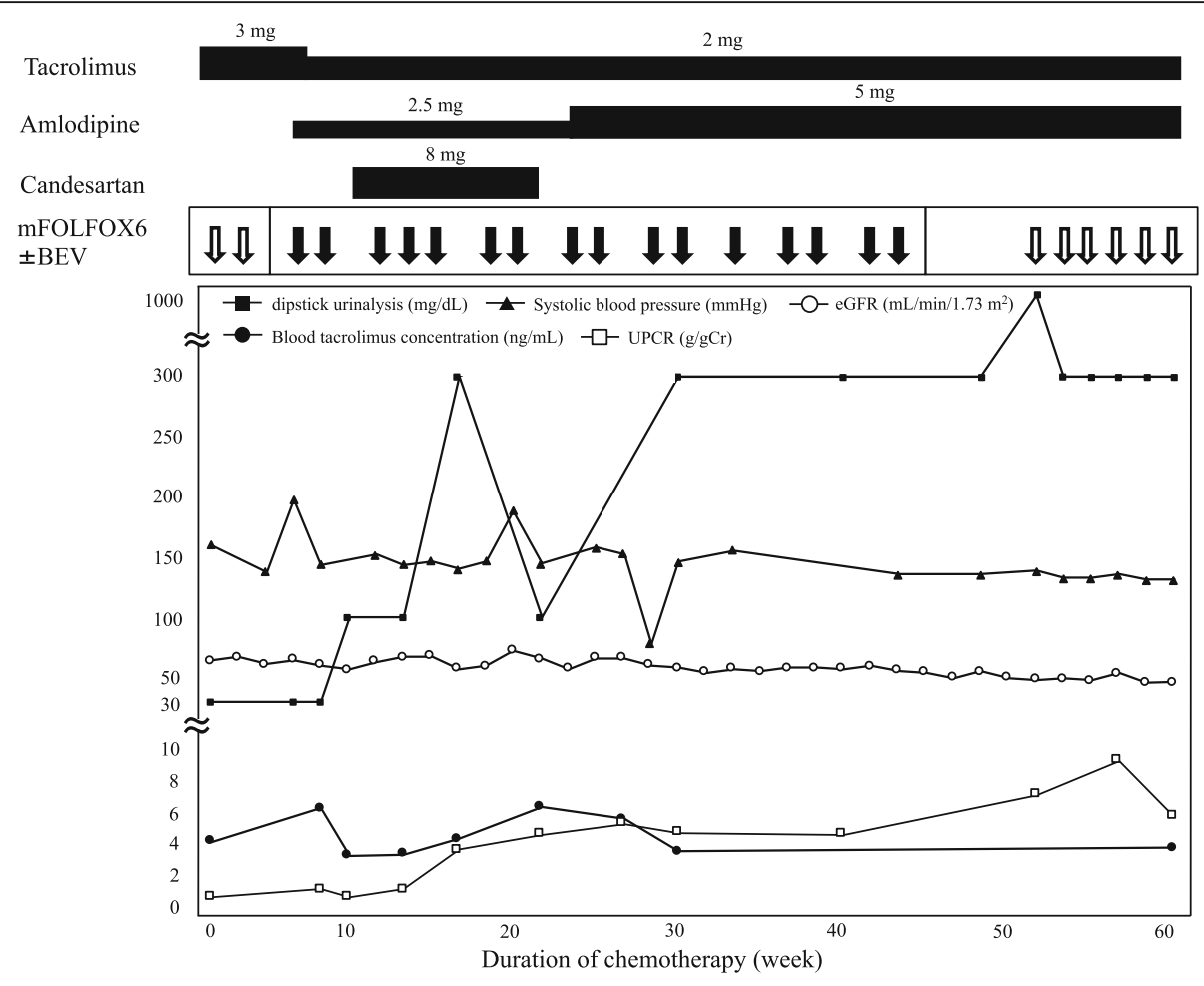

Fig. 1 Changes in proteinuria during chemotherapy. Administration of mFOLFOX6 (§); Administration of BEV + mFOLFOX6 ( $(\mathbf{l})$

recovered over time and increased to $8.9 \times 10^{9} / \mathrm{L}$ at the start of 24 cycle of mFOLFOX6 (excluding oxaliplatin).

\section{Discussion}

In this case, the patient who had been taking an immunosuppressant for a long time after kidney transplantation developed severe proteinuria on BEV administration.

$\mathrm{BEV}$ is an important drug used in the standard therapy of patients with nonresectable, advanced, or recurrent colorectal cancer. The survival of these patients is improved by combining BEV with primary and secondary chemotherapy regimens [12]. However, proteinuria is a characteristic side effect associated with BEV use. Mild or moderate proteinuria is observed at a high rate of $21-63 \%$ of patients treated with BEV [9]. It may be relieved naturally, but if symptoms persist and become severe, discontinuation of BEV should be considered. As a result, the therapeutic effect may be affected. For this reason, it is recommended that $\mathrm{BEV}$ is administered with regular urinalysis [13]. Urine test strips and 24-h urine collection tests are commonly used to test proteinuria. The package insert recommends discontinuing BEV for patients with nephrotic syndrome and temporarily suspending BEV for patients with proteinuria $\geq 2 \mathrm{~g} / 24$ - $\mathrm{h}$ (equivalent to UPCR $\geq 2 \mathrm{~g} / \mathrm{gCr}$ ). In the Evidence-Based Clinical Practice Guideline for CKD 2018 (Japanese
Society of Nephrology), proteinuria is one of the staging criteria for chronic kidney disease (CKD), which is evaluated by UPCR or quantity of urine protein measured by 24-h urine collection. UPCR is often substituted because outpatient chemotherapy makes it difficult to collect urine for 24-h [14]. In this case, urine protein concentration and UPCR were $300 \mathrm{mg} / \mathrm{dL}$ and $3.5 \mathrm{~g} / \mathrm{gCr}$ after 5 cycles, respectively, but BEV was continued. One of the reasons for this is that the decision of whether or not to administer BEV was based on the proteinuria concentration alone. UPCR has already been reported for its utility in measuring urinary protein, but there are often cases that are ignored in general practice. Furthermore, in this case, in addition to BEV administration, there were multiple risk factors for the development of proteinuria, such as a history of kidney transplantation and combined use of immunosuppressants. In such patients, regular urinalysis including UPCR should be done to determine if $\mathrm{BEV}$ can be given, and BEV administration should be actively discontinued if UPCR $\geq 2 \mathrm{~g} / \mathrm{gCr}$.

Renal pathology findings indicative of $\mathrm{BEV}$-induced proteinuria include glomerular endothelial cell exfoliation, the collapse of slit membranes formed by glomerular podocytes, and glomerular nephritis caused by renal thrombotic microangiopathy (TMA) [15]. In this case, immunosuppressants were continuously used after kidney transplantation. Calcineurin inhibitors tacrolimus and cyclosporine are known to cause nephrotoxicity 
[16]. Frequent kidney damage occurs when serum concentrations of calcineurin inhibitors remain high for long periods of time [17]. Therefore, regular dose adjustment based on serum concentration measurements is recommended. The main cause of tacrolimus-related nephrotoxicity is renal tubule damage, with elevated serum creatinine levels and electrolyte abnormalities [18]. Furthermore, since tacrolimus is known to be involved in the development of TMA [19], the combination of tacrolimus and BEV may have caused TMA additively or synergistically, causing tissue damage. However, details in this case are unknown because a renal biopsy was not performed after the onset of severe proteinuria.

Müsri et al. submitted the only case report to date concerning the course of a colorectal cancer patient who received BEV after kidney transplantation [20]. They reported severe proteinuria after BEV administration in a patient who underwent kidney transplantation, in which tacrolimus and everolimus were used as immunosuppressive agents. However, the association between serum tacrolimus concentration and proteinuria was not evaluated in that report. In our case, there were no significant differences in serum tacrolimus concentrations before and after the start of BEV administration. Moreover, there was no correlation between the serum tacrolimus concentration and proteinuria. Therefore, it is indicated that the cause of severe proteinuria is not the effect of tacrolimus concentration.

Thrombocytopenia occurred before the onset of severe proteinuria. Suspected causes of thrombocytopenia were BEV administration, tacrolimus use [21, 22], and TMA [23], but recovery was observed after withdrawal of oxaliplatin. Therefore, it was speculated that bone marrow suppression by oxaliplatin was a direct causative factor.

Previous reports have shown that the increase in blood pressure with BEV use does not correlate with the onset of proteinuria [24], and the observations in this case may be consistent with this conclusion.

This report has potential limitations. It is unclear whether both kidney transplantation and administration of calcineurin inhibitors could be risk factors of proteinuria caused by BEV. To reveal this clinical question, more case reports and clinical research are required.

The administration of BEV to cancer patients undergoing living kidney transplantation is considered to be important for prolonging survival. However, depending on the patient's medical history and the selected anticancer drug, serious side effects may occur. In this case, severe proteinuria developed. Patients with risk factors for renal impairment should have their proteinuria measured regularly to carefully assess the risks and benefits of $\mathrm{BEV}$ administration.

\section{Abbreviations}

mFOLFOX6: 5-Fluorouracil, levofolinate, and oxaliplatin; BEV: Bevacizumab; WBC: White blood cell; BUN: Blood urea nitrogen; SCr: Serum creatinine concentration; eGFR: Estimated glomerular filtration rate; UPCR: Urine protein creatinine ratio; TMA: Thrombotic microangiopathy

\section{Acknowledgments \\ Not applicable.}

\section{Authors' contributions}

$\mathrm{RO}$ conceived the study and drafted the manuscript. SN, $\Pi$, and $\mathrm{KK}$ interpreted the data and revised the manuscript critically for important intellectual content. The final version of the manuscript was read and approved by all authors.

\section{Funding}

No funding was received.

\section{Availability of data and materials}

All data generated or analyzed during this study are included in this published article.

Ethics approval and consent to participate

Not applicable.

Consent for publication

The patient consented for publication of this report.

\section{Competing interests}

The authors declare that they have no competing interests.

\section{Author details}

'Department of Pharmacy, Iwate Medical University Hospital, 2-1-1 Idaidouri, Yahaba-cho, Iwate 028-3609, Japan. ²Department of Clinical Pharmaceutics and Pharmacy Practice, School of Pharmacy, Iwate Medical University, 2-1-1 Idaidouri, Yahaba-cho, Iwate 028-3609, Japan. ${ }^{3}$ Department of Surgery, School of Medicine, Iwate Medical University, 2-1-1 Idaidouri, Yahaba-cho, Iwate 028-3609, Japan.

Received: 20 March 2020 Accepted: 14 August 2020

Published online: 04 September 2020

\section{References}

1. Pascual M, Theruvath T, Kawai T, Tolkoff-Rubin N, Cosimi AB. Strategies to improve long-term outcomes after renal transplantation. N Engl J Med. 2002;346:580-90.

2. Morales JM, Marcén R, del Castillo D, Andres A, Gonzalez-Molina M, Oppenheimer F, et al. Risk factors for graft loss and mortality after renal transplantation according to recipient age: a prospective multicentre study. Nephrol Dial Transplant. 2012;27(Suppl 4):iv39-46.

3. Kim JY, Ju MK, Kim MS, Kim NK, Sohn SK, Kim SI, et al. Clinical characteristics and treatment outcomes of colorectal cancer in renal transplant recipients in Korea. Yonsei Med. 2011:52:454-62.

4. Hicklin DJ, Ellis LM. Role of the vascular endothelial growth factor pathway in tumor growth and angiogenesis. J Clin Oncol. 2005;23:1011-27.

5. Saltz LB, Clarke S, Díaz-Rubio E, Scheithauer W, Figer A, Wong R, et al. Bevacizumab in combination with oxaliplatin-based chemotherapy as firstline therapy in metastatic colorectal cancer: a randomized phase III study. J Clin Oncol. 2008;26:2013-9.

6. Gordon MS, Cunningham D. Managing patients treated with bevacizumab combination therapy. Oncology. 2005;69:25-33.

7. Hara A, Wada T, Furuichi K, Sakai N, Kawachi H, Shimizu F, et al. Blockade of VEGF accelerates proteinuria, via decrease in nephrin expression in rat crescentic glomerulonephritis. Kidney Int. 2006;69:1986-95.

8. Veron D, Reidy K, Marlier A, Bertuccio C, Villegas G, Jimenez J, et al. Induction of podocyte VEGF164 overexpression at different stages of development causes congenital nephrosis or steroid-resistant nephrotic syndrome. Am J Pathol. 2010;177:2225-33.

9. Izzedine H, Massard C, Spano JP, Goldwasser FO, Khayat D, Soria JC. VEGF signalling inhibition-induced proteinuria: mechanisms, significance and management. Eur J Cancer. 2010;46:439-48.

10. Machado FG, Kuriki PS, Fujihara CK, Fanelli C, Arias SC, Malheiros DM, et al. Chronic VEGF blockade worsens glomerular injury in the remnant kidney model. PLoS One. 2012;7:39580. 
11. Karpe KM, Talaulikar GS, Walters GD. Calcineurin inhibitor withdrawal or tapering for kidney transplant recipients. Cochrane Database Syst Rev. 2017; 7:CD006750.

12. Esin $\mathrm{E}$, Yalcin $\mathrm{S}$. Maintenance strategy in metastatic colorectal cancer: a systematic review. Cancer Treat Rev. 2006;42:82-90.

13. Zhu X, Wu S, Dahut WL, Parikh CR. Risks of proteinuria and hypertension with bevacizumab, an antibody against vascular endothelial growth factor: systematic review and meta-analysis. Am J Kidney Dis. 2005;49:186-93.

14. Wu S, Kim C, Bear L, Zhu X. Bevacizumab increases risk for severe proteinuria in cancer patients. J Am Soc Nephrol. 2010;21:1381-9.

15. Stokes MB, Erazo MC, D'Agati VD. Glomerular disease related to anti-VEGF therapy. Kidney Int. 2008;74:1487-91.

16. Naesens M, Kuypers DR, Sarwal M. Calcineurin inhibitor nephrotoxicity. Clin J Am Soc Nephrol. 2009:4:481-508.

17. Andrews LM, Li Y, De Winter BCM, Shi YY, Baan CC, Van Gelder T, et al. Pharmacokinetic considerations related to therapeutic drug monitoring of tacrolimus in kidney transplant patients. Expert Opin Drug Metab Toxicol. 2017;13:1225-36.

18. Lee $\mathrm{CH}$, Kim GH. Electrolyte and acid-base disturbances induced by calcineurin inhibitors. Electrolyte Blood Press. 2007:5:126-30.

19. Laskin BL, Goebel J, Davies SM, Jodele S. Small vessels, big trouble in the kidneys and beyond: hematopoietic stem cell transplantation-associated thrombotic microangiopathy. Blood. 2011;118:1452-62.

20. Müsri FY, Mutlu H, Eryllmaz MK, Salim DK, Coșkun HŞ. Experience of bevacizumab in a patient with colorectal cancer after renal transplantation J Cancer Res Ther. 2015;11:1018-20.

21. Dior M, Coriat R, Mir O, Brezault C, Perkins G, Dhooge M, et al. A rare hematological adverse event induced by bevacizumab: severe thrombocytopenia. Am J Med. 2012;125:828-30.

22. Yang Y, Yu B, Chen Y. Blood disorders typically associated with renal transplantation. Front Cell Dev Biol. 2015;19:3-18

23. Morton JM, George JN. Microangiopathic hemolytic Anemia and thrombocytopenia in patients with Cancer. J Oncol Pract. 2016;12:523-30.

24. Eremia $\mathrm{V}$, Jefferson JA, Kowalewska J, Hochster $\mathrm{H}$, Haas M, Weisstuch J, et al. VEGF inhibition and renal thrombotic microangiopathy. N Engl J Med. 2008; 358:1129-36.

\section{Publisher's Note}

Springer Nature remains neutral with regard to jurisdictional claims in published maps and institutional affiliations.

Ready to submit your research? Choose BMC and benefit from:

- fast, convenient online submission

- thorough peer review by experienced researchers in your field

- rapid publication on acceptance

- support for research data, including large and complex data types

- gold Open Access which fosters wider collaboration and increased citations

- maximum visibility for your research: over $100 \mathrm{M}$ website views per year

At $\mathrm{BMC}$, research is always in progress.

Learn more biomedcentral.com/submissions 